\title{
Pleomorphic adenoma of hard palate -A case report
}

\author{
Rachana P.B ${ }^{1}$, Ramaraj P.N², Kiruba Shankar K ${ }^{3, *}$, Singh Rohit Subedar ${ }^{4}$, Vijaya Lakshmi G5 \\ ${ }^{1}$ Senior Lecturer, ${ }^{2}$ Professor \& HOD, ${ }^{3-5}$ Postgraduate Student, Dept. of Oral and Maxillofacial Surgery, KVG Dental College and \\ Hospital, Sullia, Karnataka, India \\ *Corresponding Author: \\ Email: kiruba3shankar@gmail.com
}

\begin{abstract}
Pleomorphic adenoma is the most common benign salivary gland tumour consisting of cells exhibiting the ability to differentiate into epithelial and mesenchymal cells. Parotid is the most common site of occurrence among major salivary glands and palate is the most common site of occurrence in case of minor salivary gland involvement. This article presents a case of a dome shaped swelling over the posterolateral part of hard palate which was a diagnostic challenge, and was successfully treated by surgical excision.
\end{abstract}

Keywords: Pleomorphic adenoma, Palate, Minor salivary gland.

\section{Introduction}

Palatal swelling can be developmental, inflammatory or reactive in nature. Differential diagnosis of palatal swelling includes periapical abscess, salivary gland tumours, fibro osseous lesions, carcinoma arising from maxilla/maxillary sinus and becomes a challenge for the clinician to diagnose. Here we present a case of pleomorphic adenoma of palate which was a diagnostic dilemma. Pleomorphic adenoma or mixed tumour of salivary gland is the most commonly occurring benign salivary gland neoplasm. It accounts for $53 \%$ to $77 \%$ of parotid tumours, $44 \%$ to $68 \%$ of submandibular tumours and $33 \%$ to $43 \%$ of minor gland tumours. ${ }^{2}$ The term pleomorphic adenoma suggested by Wills characterizes closely the unusual histologic pattern of the lesion. Pleomorphic adenoma is also known as Enclavoma, Brachioma, Endothelioma, Enchondroma. The aim of this article is to focus on different diagnostic method which was carried out to come to a proper diagnosis and to rule out the differential diagnosis. Uniqueness of this article is the placement of Zinc oxide eugenol pack after tumour excision which does not exist much in the literature.

\section{Case Report}

A 52 year old female patient reported to department of OMFS, with a chief complaint of painless swelling over left side palatal region since 6 months. Patient gave a history of swelling which was initially smaller in size and gradually progressed to the current size. On eliciting the past medical history, patient had umblical hernia and was admitted under department of general surgery at the same institution and referred to department of OMFS for the management of palatal swelling.

On intra oral soft tissue examination, the lesion is a single well defined dome shaped swelling of approximately $2 * 2 \mathrm{~cm}$ in size extending anteroposteriorly from mesial aspect of 26 to distal surface of 28palatally and mediolaterally from mid palatal area to palatal aspect of left maxillary posterior teeth. The surface overlying the mucosa is smooth and is not ulcerated .On palpation, all inspectory findings were confirmed and the swelling is non-tender, firm in consistency and tightly attached to the overlying mucosa. (Fig. 1). On hard tissue examination, $11,12,21,22$ was found to be missing and there is no caries or any pathology to the tooth associated with the swelling but the tooth associated was periodontally compromised with extrinsic stains. Provisional diagnosis of the swelling/lesion is given as benign salivary gland tumour.

FNAC was done which showed negative aspiration. To assess the extent of growth and bony involvement, CT-PNS was carried out which showed a homogenously enhancing mass/lesion over left posterior part of hard palate with mild bony erosion. (Fig. 2)

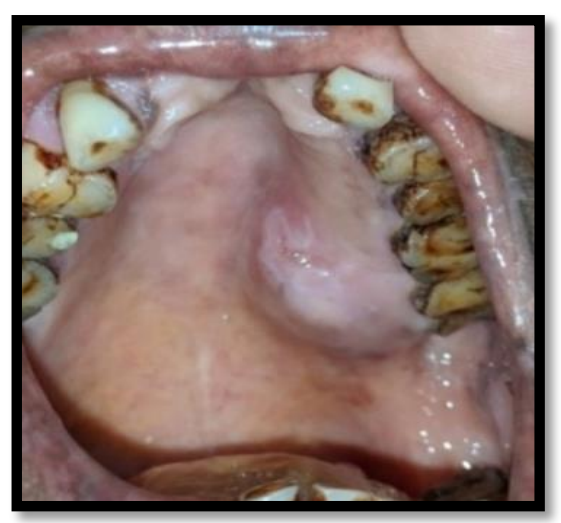

Fig. 1: Dome shaped swelling over hard palate 


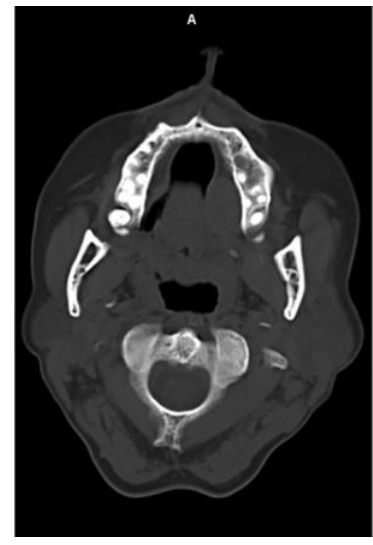

Fig. 2: Computed tomography-PNS showing the lesion over left postero lateral surface of hard palate

For confirmatory diagnosis, incisional biopsy was done which revealed the lesion to be a pleomorphic adenoma of hard palate. Under all routine preoperative investigations, surgical excision of the lesion was planned under general anaesthesia, the lesion is surgically excised with ligation of greater palatine neurovascular bundle, along with the excision of over lying normal mucosa to prevent recurrence in other minor salivary glands of that particular site (Fig. 3), followed by placement of zinc oxide Eugenol pack with an acrylic plate secured with wires to the tooth which was removed after a week and the wound was allowed to heal secondarily (Fig. 4, 5). Histopathology of the specimen confirmed the lesion to be a pleomorphic adenoma. Histopathological section showed myoepithelial cells with hyperchromatic nuclei arranged in acinar, ductal and trabeculae pattern .Connective tissue showing mucoid and myxoid material and extravagated Rbcs. (Fig. 6). Postoperative healing and possibility of recurrence could not be ruled out as the patient had not turned up for follow up visit after acrylic plate removal on $7^{\text {th }}$ postoperative day.

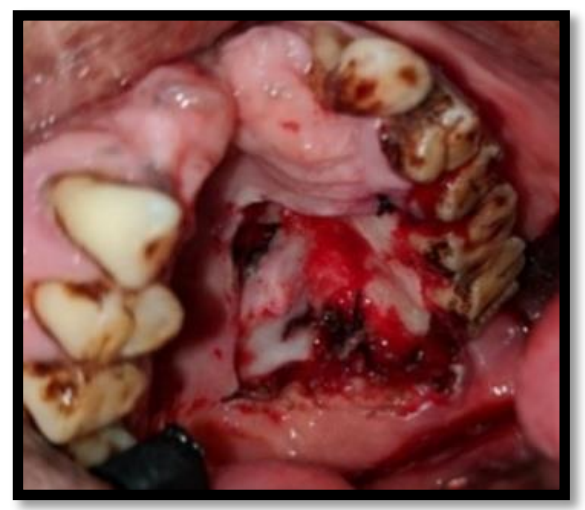

Fig. 3: Surgical excision of the lesion preserving greater platine neurovascular bundle

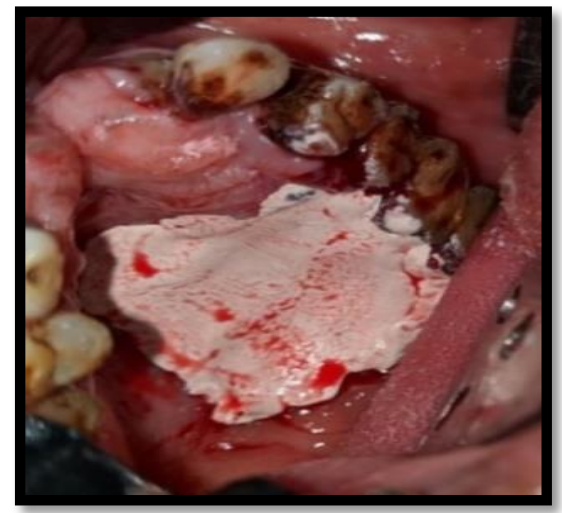

Fig. 4: Placement of zinc oxide eugenol pack

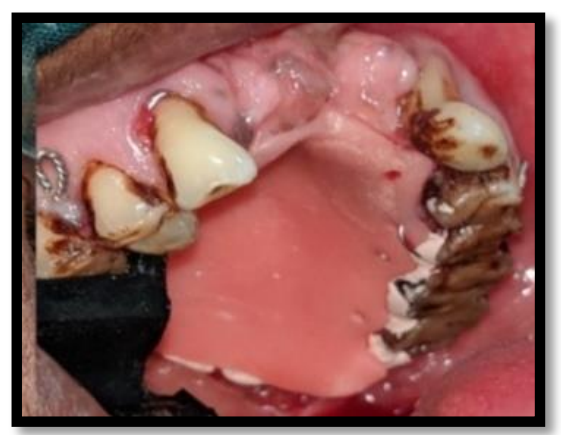

Fig. 5: Acrylic plate placed over the pack

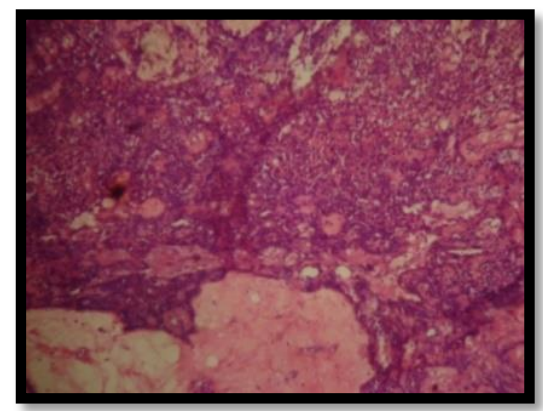

Fig. 6: Histopathologic picture showing myoepithelial cells with mucoid and myxoid material

\section{Discussion}

Pleomorphic adenoma appears as a painless, slowly growing firm mass which shows intermittent growth .Pain is not a common symptom, local discomfort occurs. The tumour occurs mostly in sixth decades of life with the average age of occurrence of about 43 years with a slight female predilection. ${ }^{4-6}$ Most common site for minor salivary gland pleomorphic adenoma is the hard palate followed by lip, buccal mucosa, floor of mouth, tongue tonsils, pharynx, retro molar area and oral cavity. ${ }^{7,8}$ Review of literature shows that Pleomorphic adenoma had also existed in Parapharyngeal space. Palatal tumours are always found on posterolateral aspect of palate presenting as smooth surface, dome shapes mass. ${ }^{9}$ It contains both 
epithelial as well as myoepithelial elements and hence considered as mixed tumour of salivary gland. ${ }^{10}$ When originating in the minor salivary glands, in most cases it occurs on the soft and hard palate due to the highest concentration of salivary glands there and is typically a firm or rubbery submucosal mass without ulceration or surrounding ulceration. ${ }^{10,11}$ Pleomorphic adenoma usually do not involve bone, but it may lead to resorption of bone due to its pressure effect. The differential diagnosis for this case includes palatal abscess, odontogenic and non-odontogenic cysts, soft tissue tumours such as fibroma, lipoma, neurofibroma, neurilemmoma, and lymphoma as well as other salivary gland tumors. ${ }^{12}$ Periapical abscess is ruled out because there was no evidence of periapical pathology associated with the tooth in IOPA. Both odontogenic and non-odontogenic cysts is ruled out because, FNAC revealed negative aspiration. Malignant tumour extending from maxillary sinus is ruled out because the mucosa overlying the lesion is not ulcerated. Diagnosis of pleomorphic adenoma is based on history, clinical examination and always to be confirmed with FNAC and histopathology. Computed tomography scan is an adjuvant diagnostic aid helpful in revealing about the size and extension of the tumour to the adjacent structures and to rule out bony involvement. Confirmatory diagnosis will depend on histopathological examination. Various treatment and reconstruction protocol has been suggested in the literature. Management of pleomorphic adenoma of palate should be wide local excision of the lesion with $1 \mathrm{~cm}$ negative margin at the periphery along with overlying normal mucosa. Placement of tincture benzoin gauge over the denuded bone after surgical excision is also given in the literature ${ }^{13}$.In our case, Zinc oxide Eugenol pack with acrylic plates has been used after surgical excision of the lesion because of mild bony erosion noted in CT scan and also for the antiseptic property of ZNOE. It protects the surgical site from trauma during speech and mastication and also reduces postoperative pain and haemorrhage. Bony involvement usually do not occur in case of palatal pleomorphic adenoma and bone removal becomes unnecessary until involved. Large fenestration defect if occurs, could be covered by a palatal island flaps. Prognosis of palatal pleomorphic adenoma is usually good, does not recur after adequate surgical removal. ${ }^{14}$ Recurrence if at all occurs can be attributable to inadequate surgical techniques such as simple enucleation leaving behind microscopic pseudopod-like extensions, capsular penetration, and tumour rupture with spillage of tumor cells. ${ }^{15}$

\section{Conclusion}

Pleomorphic adenoma of minor salivary gland is one of the lesion among various palatal swelling. Proper clinical, radiological and histopathological examination will lead us to a correct diagnosis. Surgical excision of the lesion, followed by long term follow up is necessary because of possibility of recurrence.

\section{References}

1. Scully C, Porter S. Orofacial Disease: Update for the Dental Clinical Team: 7. Complaints affecting particularly the palate or gingivae. Dent Update 1999;26:308-13.

2. Lucas RB. Pathology of tumors of the oral tissues. 4th ed. Edinburgh: Churchill livingstone1984:298.

3. Sharma Y, Maria A, Chhabria A. Pleomorphicadenoma of the palate. Natl J Maxillofac Surg 2011;2:169-71.

4. Torske K. Benign neoplasm of the salivary glands. In: Thompson LDR(ed.) head and neck pathology, 1st edn. Elsevier, Philadelphia, 2006:295-300.

5. Seifert GD. Multiple tumors of the salivary glands: terminology and nomenclature. Eur J Cancer Oral oncol 1996;32:3-7

6. Compagno JW. Intranasal mixed tumor. Am J Clin Pathol 1977;68:213-8.

7. Spiro SH. Salivary neoplasms: overview of a 35 -year experience with 2,807 patients. Head Neck Surg 1986;8(3):177-84.

8. Cohen MA.Pleomorphic adenoma of the cheek. Int J Oral Maxillofac Surg 1986;15(6):777-9.

9. Ogata H, Ebihara S, Mukai K. Salivary gland neoplasms in children. Jpn J Clin Oncol 1994;24:88-93.

10. Shafer, Hine, Levy. Shafer's Textbook of Oral Pathology: 4th ed. Japan, W.B. Saunders Co.1983.

11. Vellios F, Shafer WG. Tumors of minor salivary glands. Surg Gynecol Obstet 1959;108:450-6.

12. Sreenivas SD. Pleomorphic adenoma of the palate $-\mathrm{a}$ case report. J Ind Dent Asso 2011;5:4.

13. ogesh Sharma, Anisha Maria, AmitChhabriaPleomorphic adenoma of the palate Natl J Maxillofac Surg 2011;2(2):169-71

14. Chaudhari S, Hatwal D, Ashok, Suri V. Pleomorphic adenoma of hard palate: A report of four cases. Int J Case Reports Images 2013;4(2):90-4.

15. Mubeen K, Vijayalakshmi KR, Patil AR, Giraddi GB, Singh C. (2011) Benign pleomorphic adenoma of minor salivary gland of palate. J Dent Oral Hyg 3:82-8. 